\title{
Not " $Z$ " end of the story: Do $Z$ scores help to guide surgical decisions about the ascending aorta in patients with bicuspid aortic valve?
}

\author{
Siddharth K. Prakash, MD, PhD, ${ }^{a}$ and Anthony L. Estrera, MD, FACS ${ }^{b}$
}

From the Departments of ${ }^{\mathrm{a}}$ Internal Medicine, and ${ }^{\mathrm{b}}$ Cardiothoracic and Vascular Surgery, McGovern Medical School at The University of Texas Health Science Center at Houston (UTHealth), Houston, Tex.

Supported by 1R01HL137028 (to S.K.P.), "The Genetic Basis of Early Onset Bicuspid Aortic Valve Disease," with resources from the International Bicuspid Aortic Valve Consortium (BAVCon).

Disclosures: Dr Estrera is a consultant for WL Gore and Associates. The other author has nothing to disclose with regard to commercial support.

Received for publication Sept 18, 2017; accepted for publication Oct 6, 2017; available ahead of print Nov 3, 2017.

Address for reprints: Anthony L. Estrera, MD, FACS, Department of Cardiothoracic and Vascular Surgery, McGovern Medical School at UTHealth, 6400 Fannin St, Suite \#2850, Houston, TX 77030 (E-mail: Anthony.L. Estrera@uth.tmc.edu).

J Thorac Cardiovasc Surg 2018;155:560-1

$0022-5223 / \$ 36.00$

Copyright (c) 2017 by The American Association for Thoracic Surgery

https://doi.org/10.1016/j.jtcvs.2017.10.030

More than one third of patients with a bicuspid aortic valve (BAV) have a dilated ascending aorta. ${ }^{1}$ The prevalence of severe aortic valve disease and acute aortic dissections is increased in patients with BAV, and these occur at younger ages than in patients with tricuspid aortic valves. ${ }^{2}$ In view of these risks, prophylactic repair of the proximal aorta has been proposed to prevent dissections and deaths. 3,4

Current guidelines state that it is reasonable to replace the ascending aorta in patients with BAV undergoing aortic valve replacement surgery if the ascending diameter is larger than $4.5 \mathrm{~cm} .{ }^{5-7}$ However, these recommendations are problematic for patients with BAV because they are based on nonrandomized studies, are largely extrapolated from experiences with unrelated disorders (eg, Marfan syndrome), and rely on the unadjusted aortic diameter, which is not a reliable predictor of dissection. ${ }^{8}$ Uncertainty about elective repairs in patients with BAV is compounded by the relatively low rates of dissections and mortality in BAV cohorts. Surgical approaches to the ascending aorta in BAV cases are not uniform, reflecting significant knowledge gaps about the natural history of BAV aortopathy. ${ }^{9}$

The current report by Sievers and colleagues, ${ }^{10}$ as the largest single institutional experience to date, presents a unique opportunity to evaluate decision analysis models in a surgically managed cohort of patients with BAV. Their 17-year data showed that the addition of ascending aortic interventions (AAIs) to aortic valve replacement is generally safe and may even prevent some late deaths that could be due to aortic events. They also confirmed previous data that outcomes tend to be worse for patients with aortic regurgitation. ${ }^{11,12}$ In an attempt to improve the diameter-based guidelines, the authors applied a clinical algorithm to recommend AAI that incorporates $Z$ scores based on age, gender, body size, family history of aortic disease, valve and aortic morphology, and apparent aortic wall friability.

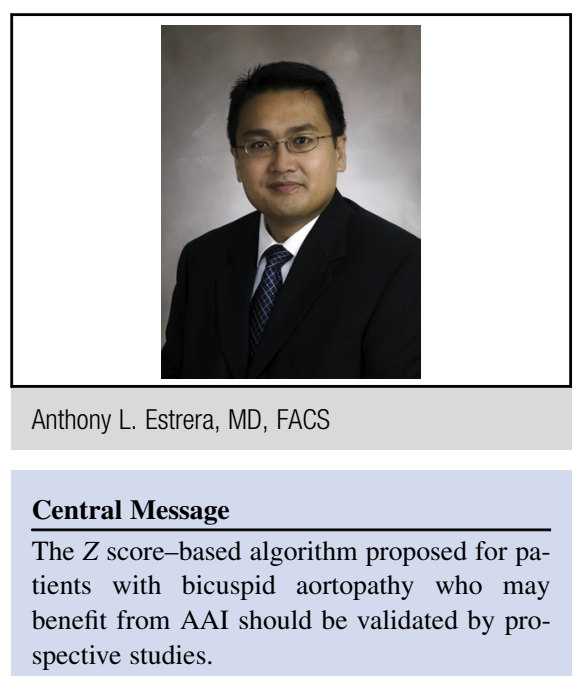

See Article page 549

In this report, several important observations were made leading to specific implications.

1. The authors' more liberal approach using $Z$ scores led to AAI in an additional $8 \%$ of the cohort whose absolute ascending diameters were less than $4.5 \mathrm{~cm}(97 / 1213$ patients). This predominately involved female and younger patients. Thus, $17 \%$ of those patients who underwent AAI group involved aortic diameters less than $4.5 \mathrm{~cm}$.

2. No differences in early morbidity or mortality were observed when concomitant AAI was performed with the aortic valve procedure. With an overall early mortality of $1 \%$ and incidence of stroke of $0.5 \%$ in either group, concomitant AAI can be performed safely in experienced centers.

3. No reinterventions were observed in the ascending aortic replacement group. No statistical differences in late aortic reinterventions were observed in either group (AAI vs no AAI). When performing AAI, ascending aortic replacement should be considered over ascending aortoplasty (AOP), because AOP appeared less durable.

4. Hemiarch replacement was performed in $11 \%$ of the AAI group (65/577), but only 1 type A dissection (in the AOP group) occurred during late follow-up. This suggests that the BAV aortopathy may predominately be isolated to the ascending aorta. This has implications 
on whether open distal anastomosis and circulatory arrest are required during ascending repair with BAV.

5. Only 2 acute type A aortic dissections were confirmed in late follow-up for the entire cohort; 1 patient each in the AOP and no AAI groups. This suggests that the overall incidence of late type A aortic dissection was low (2/1693) in this series but, as appropriately acknowledged by the authors, could have been higher if complete autopsy data had been obtained.

On the basis of these observations, the authors advocate for $Z$ scores as a tool to augment risk stratification and inform clinical decisions about the ascending aorta in patients with BAV. These findings raise new questions that should ultimately be addressed in additional prospective studies. The impact of BAV morphology on clinical presentation and surgical decisions was not specified. In the follow-up period, they were unable to determine whether their algorithm-based management strategy resulted in fewer aortic events because the overall number of events was low. Because their strategy incorporating a $Z$ score led to a lower threshold for intervention, especially in younger and female patients, it should be emphasized that their approach needs further prospective validation and, thus, is not currently generalizable. $Z$ scores were calculated retrospectively and played no role in decision making in the study cohort. Furthermore, other risk factors, such as family history and aortic tissue frailty, may supersede aortic dimensions in younger patients.

Ultimately, decisions about AAI are complex and require additional considerations, such as baseline surgical risk and patient preferences. Management of aortopathies based on size-adjusted aortic dimensions is already routine in pediatric patients and in patients with Turner syndrome. The proposal by Sievers and colleagues ${ }^{10}$ is a valuable first step toward a strategy to incorporate similar risk models into the surgical management of BAV aortopathy.

\section{References}

1. Michelena HI, Desjardins VA, Avierinos JF, Russo A, Nkomo VT, Sundt TM, et al. Natural history of asymptomatic patients with normally functioning of minimally dysfunctional bicuspid aortic valve in the community. Circulation. 2008;21:2776-84.

2. Fedak PW, Verma S, David TE, Leask RL, Weisel RD, Butany J. Clinical and pathophysiological implications of a bicuspid aortic valve. Circulation. 2002; 106:900-4.

3. Borger MA, Preston M, Ivanov J, Fedak PW, Davierwala P, Armstrong S, et al. Should the ascending aorta be replaced more frequently in patients with bicuspid aortic valve disease. J Thorac Cardiovasc Surg. 2004;128:677-83.

4. Svensson LG, Kim KH, Blackstone EH, Rajeswaran J, Gillinov AM, Mihaljevic T, et al. Bicuspid aortic valve surgery with proactive ascending aorta repair. J Thorac Cardiovasc Surg. 2011;142:622-9, e1-3.

5. Nishimura RA, Otto CM, Bonow RO, Carabello BA, Erwin JP, Guyton RA, et al. 2014 AHA/ACC Guideline for the Management of Patients With Valvular Hear Disease: a report of the American College of Cardiology/American Heart Association Task Force on Practice Guidelines. Circulation. 2014;129:2440-92.

6. Nishimura RA, Otto CM, Bonow RO, Carabello BA, Erwin JP, Fleisher LA, et al. 2017 AHA/ACC Focused Update of the 2014 AHA/ACC Guideline for the Management of Patients With Valvular Heart Disease: A Report of the American College of Cardiology/American Heart Association Task Force on Clinical Practice Guidelines. J Am Coll Cardiol. 2017;70:252-89.

7. Erbel R, Aboyans V, Boileau C, Bossone E, Bartolomeo RD, Eggebrecht H, et al. 2014 ESC Guidelines on the diagnosis and treatment of aortic diseases: document covering acute and chronic aortic diseases of the thoracic and abdominal aorta of the adult. The Task Force for the Diagnosis and Treatment of Aortic Diseases of the European Society of Cardiology (ESC). Eur Heart J. 2014;35: 2873-926.

8. Pape LA, Tsai TT, Isselbacher EM, Oh JK, O'gara PT, Evangelista A, et al. Aortic diameter $>$ or $=5.5 \mathrm{~cm}$ is not a good predictor of type A aortic dissection: observations from the International Registry of Acute Aortic Dissection (IRAD). Circulation. 2007;116:1120-7.

9. Verma S, Yanagawa B, Kalra S, Ruel M, Peterson MD, Yamashita MH, et al. Knowledge, attitudes, and practice patterns in surgical management of bicuspid aortopathy: a survey of 100 cardiac surgeons. J Thorac Cardiovasc Surg. 2013 146:1033-40.e4.

10. Sievers H-H, Stock S, Stierle U, Klotz S, Charitos EI, Diwoky M, et al. Longerterm results, $\mathrm{z}$ scores, and decision nomograms for treatment of the ascending aorta in 1693 bicuspid aortic valve operations. J Thorac Cardiovasc Surg. 2018;155:549-59.e2.

11. Girdauskas E, Disha K, Raisin HH, Secknus MA, Borger MA, Kuntze T. Risk of late aortic events after an isolated aortic valve replacement for bicuspid aortic valve stenosis with concomitant ascending aortic dilation. Eur J Cardiothorac Surg. 2012;42:832-7.

12. Guzzardi DG, Verma S, Fedak PW. Bicuspid aortic valve aortopathy: mechanistic and clinical insights from recent studies. Curr Opin Cardiol. 2017;32: 111-6. 